PATHOLOGICAL Functional Pathology.-By Albion Walter Hewlett, M.A., M.D., B.S. Revised Edition. 1928. New York \& London: D. Appleton and Co., Pp. 787 with 164 illustrations. Available from Butterworth \& Co., Calcutta. Price Rs. 26-4 net.

THIs, the third edition of this comprehensive book dealing with the changes in the functions presented by patients suffering from internal diseases, is very welcome. Although the plans for complete revision were outlined by Dr. Hewlett himself, owing to his untimely death, this work had to be carried out by a board composed of a number of his colleagues. The revision of a book like this is a difficult task as it involves a systematic consideration of all the recent advances in the different realms of applied physiology, biochemistry, immunology, hrematology and clinical medicine. The revising board have, however, done justice to all these subjects as presented in the book and the physician gets an insight into various physiological concepts which are so essential to the rational interpretation of symptomatology in modern medicine. The chapter on the dynamics of the heart muscle is fairly lucid but in places the subject-matter appears to be summarily dealt with. 'The study of capillaries has not received proper attention, and in view of the fact that a lot of work is done on the vitamins this subject might have received fuller consideration. The chapter on metabolism, especially the section on acid-base equilibrium, is very instructive. The chapter on pernicious anæmia summarises the confusing and rapidly growing literature on the subject. The chapters on hæmatology and immunology are very comprehensive; although the recent conceptions about the pituitary and gonads have not been included, the chapter on endocrinology, on the whole, is worth reading. The bibliography appended at the end of each chapter needs special mention. The references are mainly collected from English books and periodicals and ought to be most useful to the English-reading population.

\section{LABORATORY DIAGNOSIS AND EXPERIMENTAL} METHODS IN TUBERCULOSIS.-By Henry Stuart Willis. London: Baillière, Tindall and Cox. 1928. Pp. XXV plus 330 with 25 figures in the text. Price 16s. net.

THIs well-illustrated book is written by an author Whe considerable laboratory experience in tuberculosis. of aims of the book are twofold, to describe some nof the more important methods of the laboratory diagnosis of tuberculosis and to consider some of the more experint procedures and principles involved in the experimental study of the infection.

The first chapter gives a useful description of the various exudates and transudates found in tuberculosis The the methods of obtaining and examining them fully demonstration of tubercle bacilli by staining is chlly discussed in the second, and in the two following animas the discovery of bacilli by concentration anc bacill inoculation are described. Thereafter the its growth are dealt with.

is In the third part of the volume, diagnosis by tuberculin and discussed and in the fourth tuberculo-complement Ther serological tests are dealt with.

The fifth part is devoted to the inoculation of animals usef the tubercle bacillus. In this section there is a tion description of anatomical methods for the injecvital of animals with coloured injection masses, and mentaining is described; there are also a few stateThe concerning allergy and immunity to tuberculosis. fifteenth description of histological technique in the a list chapter is excellent and the book ends with very of equipment for a tuberculosis laboratory and a complete bibliography.

The style is lucid and abstruse parts of the subject hints which to understand. There are many practical ing on which will be found useful even by those workFor other diseases besides tuberculosis.

side the thorough understanding of the laboratory side of tuberculosis, no better book could be recommended to the medical practitioner or student and it will be found a useful work of the reference on the bookshelf of the experimental laboratory.

The following quotation from the introduction by another worker at the Johns Hopkins University well describes the scope of the book:- "It is not to be doubted that we have now passed the time when the needs of the worker, interested with any of the myriad facets of tuberculosis, can be best served by a multitude of unrelated sketches and references scattered over and throughout a terrain that is as long and broad as the multipartite divis:ons of modern medicine. A germ that habitually bears down upon almost every organ and tissue of the body necessarily creates a corpus of diagnostic method that is commensurate with the unrivalled multiplicity of its pathological and clinical manifestations. 'The works on urology will present their share of the diagnostic procedures of tuberculosis, the works on orthopædics theirs, on gastro-enterology theirs, and so on; until to-day the laboratory diagnosis of the infection can be got at only in discouragingly piecemeal fashion by practitioner, student, or professional technician. For bringing together within a single volume these numerous diversified methods and for appraising them to the enlightenment and profit of the unspecialized worker, Doctor Willis deserves the thanks of the medical profession."

E. M.

\section{VARICOSE VEINS.-By Ronald Thornhill, M.B.} Ch.B. London: Bailliere, Tindall and Cox. 1929. Pp. XI plus 63 with 1 figure. Price 5s. net.

'THIs book deals with varicose veins "and their treatment by empty vein injection." It is one of the many replies which are constantly being made to those unthinking people with cramped intelligence, who say that it is not likely that any essential advance will be made in treatment by medical men when it is to the patient's advantage and their own disadvantage! Sir Berkeley Moynihan in a foreword states that "a new, simple, safe, quick device has been found for dealing with conditions formerly , remediable only by extensive and protracted methods."

The author speaks from a large experience, and discusses in successive chapters the etiology and pathology of varicose veins and the details of the injection treatment. The quinine urethane injections are usually employed, but it is probable that even better chemical solutions than this will be discovered. Many thousands of cases have now been treated; so that the method is based on a satisfactory foundation; above all its safety is assured, for cases of embolism are almost unknown.

Medical practitioners will welcome this small book as a guide to a new and efficient method of treatment for a condition which may be distressing and difficult to deal with by operative procedures.

\section{F. P. C.}

\section{RESEARCHES IN POLYNESIA AND MELANESIA PARTS V-VII.-By P. A. Buxton, M.R.C.S. D.T.M. \& H. Published by the London School of Hygiene and Tropical Medicine. 1928. Pp. XI} plus 139 illustrated. Price. 9s. net.

"Researches in Polynesia and Melanesia" embodies the results of the investigations in Samoa, Tonga the Ellice Group and the New Hebrides in the years 1924, 1925; and parts V-VII under Professor Buxton's authorship are got up together in a neat volume of 139 pages with 27 text figures-No. 2 of the memoir series of the London School of Hygiene and Tropical Medicine.

Part $V$ of the volume which is devoted to studies in filariasis is divided into the following sub-divisions (a) Methods, (b) Normals, (c) Pathological conditions, (d) Filariasis in Oceania, and (c) Summary. In the "Foreword" the author explains that though according to their original programme the study of filarias:s was not intended, a stay of some months in the Samoan islands impressed on him the necessity to devote some attention to that disease and that filariasis is discussed in the book in relation to the other work done in Oceania. 